\title{
Closer and closer? Maternal immunization: current promise, future horizons
}

\author{
Cyril Engmann ${ }^{1,2,3} \cdot$ Jessica A. Fleming ${ }^{4} \cdot$ Sadaf Khan ${ }^{1} \cdot$ Bruce L. Innis $^{4} \cdot$ Jeffrey M. Smith ${ }^{5} \cdot$ Joachim Hombach $^{6}$. \\ Ajoke Sobanjo-ter Meulen ${ }^{7}$
}

Received: 4 November 2019 / Revised: 26 March 2020 / Accepted: 27 March 2020 / Published online: 27 April 2020

(c) The Author(s), under exclusive licence to Springer Nature America, Inc. 2020

\begin{abstract}
This state-of-the art manuscript highlights our current understanding of maternal immunization-the practice of vaccinating pregnant women to confer protection on them as well as on their young infants, and thereby reduce vaccine-preventable morbidity and mortality. Advances in our understanding of the immunologic processes that undergird a normal pregnancy, studies from vaccines currently available and recommended for pregnant women, and vaccines for administration in special situations are beginning to build the case for safe scale-up of maternal immunization. In addition to well-known diseases, new diseases are emerging which pose threats. Several new vaccines are currently under development and increasingly include pregnant women. In this manuscript, targeted at clinicians, vaccinologists, scientists, public health practitioners, and policymakers, we also outline key considerations around maternal immunization introduction and delivery, discuss noninfectious horizons for maternal immunization, and provide a framework for the clinician faced with immunizing a pregnant woman.
\end{abstract}

\section{Introduction}

Of all the contributions made to global health, immunization has had one of the most profound impacts on morbidity and mortality worldwide [1,2]. Current estimates show that immunization against diphtheria, tetanus, pertussis, and

Cyril Engmann

cengmann@path.org

1 Maternal, Newborn, Child Health and Nutrition, PATH, Seattle, WA, USA

2 Department of Pediatrics, University of Washington School of Medicine, Seattle, WA, USA

3 Department of Global Health, University of Washington School of Public Health, Seattle, WA, USA

4 Center for Vaccine Innovation and Access, PATH, Seattle, WA, USA

5 Maternal, Newborn and Child Health, Bill \& Melinda Gates Foundation, Seattle, WA, USA

6 Immunization, Vaccines and Biologicals, World Health Organization, Geneva, Switzerland

7 Maternal Immunization and Pneumonia, Bill \& Melinda Gates Foundation, Seattle, WA, USA measles prevents $\sim 2-3$ million deaths annually [3]. Yet, there remains much to be done. Infectious diseases are still a leading cause of death in children under 5 years of age, and more than four million infants die before their first birthday each year worldwide; $63 \%$ of these deaths occur within the first month of life [4]. Maternal immunization-the practice of vaccinating women during pregnancy-has the potential to significantly reduce neonatal mortality when infants are dependent on maternally transferred antibodies for protection. Recent advances in the field could change the way we protect mothers and their infants and potentially save thousands of lives every year.

\section{Maternal Immunization}

Every pregnant woman deserves an optimal pregnancy, a safe delivery, and a healthy baby. Every child deserves the opportunity to survive and thrive [5]. Maternal immunization is this principle turned into action.

Pregnant women and young infants have increased susceptibility to certain infectious diseases and/or are at heightened risk of experiencing severe disease. In women, some of this increased vulnerability is due to pregnancyassociated hormones interacting with immune responses [6]; 
by contrast, in infants, immature immune systems require time and often multiple vaccine doses to mount adequate responses to many infectious diseases [7]. Maternal immunization can address this vulnerability by offering protection to a woman and her young infant by passive infant immunity conferred through the active transfer of antibodies, specifically immunoglobulin $\mathrm{G}$ ( $\mathrm{IgG})$, from the mother across the placenta [8]. IgG persists through the first few, most vulnerable months of life before degrading to unprotective levels. While some definitions of maternal immunization include protection conferred through breast milk, this discussion will be restricted to vaccines and the subsequent protection through placental transfer of maternal antibodies.

Since its inception in 1977, the World Health Organization's (WHO) Expanded Programme on Immunization (EPI) has worked to prevent childhood illnesses through vaccination during infancy and childhood [9]. And while childhood vaccinations remain a critical priority, global interest recently has grown to promote health throughout the full life course by expanding vaccination to other age groups. Such "life-course" vaccination includes women before, during, and after pregnancy, as well as newborns, children, adolescents, and older people [10]. These populations, many of which are not covered by current immunization strategies, face greater vulnerability to infectious diseases. The 1918 influenza pandemic and the 2009-2010 influenza A/H1N1 outbreak, for instance, disproportionately affected mothers, fetuses, young children, and the elderlyproviding compelling evidence for an expanded life-course approach [10, 11].

\section{Immunological principles underlying maternal immunization}

During pregnancy, there is a complex and dynamic immunological interaction between the mother and her fetus. Key principles that underly maternal immunization are outlined below.

\section{Maternal aspects}

Half of the total fetal antigen load is inherited paternally, which the maternal immune system perceives as "foreign" [12]. In pregnant immunocompetent women, many immunologically adaptive processes occur in a synchronized fashion to ensure the mother can tolerate the presence of these paternally derived antigens. Key among these processes is an increased concentration of sex hormones such as estrogen and progesterone, which induce a shift in maternal pro- and antiinflammatory responses [12] Typically, pro-inflammatory responses are a prominent feature of the first trimester, and anti-inflammatory responses are more prominent in the second and third trimesters [13]. During pregnancy, there is a rise in sex hormone levels, which, in addition to the shift in maternal pro- and anti-inflammatory responses, modulates the balance between type 1 helper (Th1) cells necessary for cellmediated immunity and type 2 helper (Th2) cells necessary for humoral immunity. Increases in estradiol result in increases in Th2 cells, which then suppress cytotoxic $\mathrm{T}$ lymphocytes and stimulate B lymphocytes to increase production of antibodies that are then transferred across the placenta to the fetus [14].

\section{Placenta}

Emerging evidence suggests the placenta plays an active role in immunologic reactions and can interact and respond to pathogens [15]. For example, local immunologic mechanisms mediated at the feto-maternal junction help protect the fetus from rejection, while cytokines provide the required growth factors necessary for fetal implantation in the placenta. Several factors can influence the placenta's role in immunity [15]. Maternal infection with malaria or HIV, for instance, decreases the placenta's ability to transport IgG by impairing antibody Fc (crystallizable fragment) receptor function, whereas higher levels of total maternal IgG reduce transfer of antigen-specific IgG by competitively binding to placental Fc receptors [16]. IgG transfer across the placenta also appears to differ by subtype. For example, IgG1, which is induced by protein antigens such as tetanus toxoid, is more efficiently transferred than $\operatorname{IgG} 2$, which is induced by lipopolysaccharide antigens such as those in encapsulated bacteria [16].

\section{The fetus and young infant}

The immature immune system of the developing fetus and young infant cannot mount a full-blown protective response to pathogens. Fetal and neonatal $\mathrm{T}$ cells display $\mathrm{Th} 2$ responses that are ineffective against intracellular pathogens, and antibody responses to bacterial polysaccharides are ineffective [16]. This results in the fetus and young infant relying on supplemental maternal protection provided by the active transport of $\operatorname{IgG}$ across the placenta. IgG efficiently crosses the human placenta via syncytiotrophoblast cells that are in contact with maternal blood [16]. Circulating maternally derived $\mathrm{IgG}$ is internalized in endosomes and binds to neonatal $\mathrm{Fc}$ receptors, which are expressed on the internal endosomal surface. These endosomes fuse with the membrane on the fetal aspect of the syncytiotrophoblast and release $\mathrm{IgG}$, which then passes through villous stroma and fetal capillary endothelium to enter the fetal circulation [16]. There is active transport of IgG during the second and third trimesters, with IgG flux enhanced significantly after 32 weeks of gestation. Some 
studies report the concentration of fetal $\operatorname{IgG}$ in the late second trimester and early third trimester is $25-50 \%$ lower when compared to term infants [17]. When a fetus reaches full term, its IgG concentrations are sometimes even greater than those in the maternal circulation, because of the active transport mechanism [18]. Multiple factors can affect the transfer, including placental integrity, maternal noninfectious diseases, total maternal IgG concentration, IgG subtype, presence of neonatal $\mathrm{Fc}$ receptors, nature of the antigen, and timing of vaccination or infection [8].

\section{Vaccines currently available and recommended for use in pregnant women}

The safety and effectiveness of immunization during pregnancy against diphtheria, pertussis, tetanus, and influenza is well documented, and these vaccines are regularly included in national routine immunization schedules. Yet, uptake is inconsistent even among these recommended vaccines. For example, uptake of tetanus toxoid vaccine has been successful, while high coverage of pertussis and influenza vaccines is still limited by cost concerns, a paucity of disease data, lack of clear guidelines for health care providers, vaccine hesitancy on the part of some pregnant women, and decreased global drive and commitment. Issues related to immunization against these different pathogens are outlined below.

\section{Tetanus}

The vast majority of the 30,848 cases of neonatal tetanus reported in 2017 occurred in low-income settings, where poor hygienic or cultural practices following birth may be prevalent (e.g., cutting the umbilical cord with a nonsterilized blade or applying a local poultice or remedy to the exposed umbilical stump) [19]. Tetanus is characterized by painful muscle spams and rigidity caused by blockade of inhibitory neurons by tetanus toxin, thus resulting in excitatory motor neurons lacking any counterbalance or modulation [20]. The average incubation period is 3-21 days. Untreated, neonatal tetanus usually results in death from respiratory failure; however mortality can be significantly attenuated through supportive care and treatment [21].

Maternal immunization with tetanus toxoid-containing vaccine (TTCV) represents a global health triumph. WHO estimates that from 2000 to the end of 2017, there was an $85 \%$ decrease in neonatal tetanus deaths. This was due, in large part, to a globally sustained initiative called the Maternal and Neonatal Tetanus Elimination initiative, which targeted pregnant women and women of reproductive age with TTCV [22]. Pregnant women and their newborn infants are protected from birth-associated tetanus if the mother received either six TTCV doses during childhood or five doses if first vaccinated during adolescence (documented by card, immunization registry, and/or history), before the time of reproductive age. While complete eradication remains unlikely because of the ubiquitous and highly resistant nature of the causative pathogen, Clostridium tetani, efforts are underway to reduce the global burden of this devastating disease through a four-pronged strategy [23]:

1. Routine vaccination of pregnant women with TTCV.

2. Supplementary immunization activities, such as immunization of all women of childbearing age in areas at highest risk of maternal and neonatal tetanus and school- or community-based immunization.

3. Safe deliveries attended by a skilled birth attendant who uses sterilized equipment/materials and clean cord care practices.

4. Improved neonatal tetanus surveillance and enhanced preventive strategies with vaccination, and improvement of perinatal care and post-exposure prophylaxis in high-risk areas-especially among the most vulnerable populations.

As a result, as of March 2018 maternal and neonatal tetanus has been eliminated from all but 13 countries (where elimination is defined as a neonatal tetanus rate of $<1$ case per 1000 live births in each district of the country) [22].

Because regular booster doses with TTCV provide longterm immunity, and neonates born to women who lack sufficiently high levels of circulating tetanus IgG antibodies are at heightened risk of neonatal infection, WHO recommends that all women of childbearing age in highrisk areas for maternal and neonatal tetanus receive three doses over a 12-month period. Additional guidance states that pregnant women with an inadequate or unknown vaccination history should receive two doses of TTCV, at least 1 month apart, with the first dose as early in pregnancy as possible [22].

\section{Pertussis}

Pertussis is an endemic disease globally, and highly contagious. Pre-vaccination, it often affects children in their first years of life and clinically is characterized by paroxysmal coughing spells, inspiratory whoop, and post-tussive vomiting [24]. Modeled estimates indicate that $\sim 24$ million cases occurred in 2014 , accompanied by 160,700 deaths in children under the age of five [25]. The highest burden was in Africa, where an estimated 7.8 million (33\% of total) cases and 92,500 (58\% of total) deaths occurred that year. Approximately 5.1 million (21\%) estimated pertussis cases and $85,900(53 \%)$ estimated deaths were in infants younger 
than 1 year, many of whom had not started or completed their primary immunization schedules [25].

WHO recommends maternal pertussis immunization take the form of a combined tetanus-diphtheria-acellular pertussis (Tdap) vaccine, and function as a complementary intervention to timely infant immunization in countries or settings with high or increasing infant morbidity or mortality from pertussis. Maternal immunization should occur in the second or third trimester, or at least 15 days before the end of the pregnancy, though there are national variations to this recommendation [25, 26]. For example, the United States recommends Tdap vaccination during each pregnancy regardless of previous vaccination status, and while 27-36 weeks is promoted as the ideal time frame, vaccination can be administered at any time. Argentina, Ireland, and Australia also recommend Tdap vaccination during each pregnancy; however, the time frames vary: Argentina starting at 20 weeks of pregnancy, Ireland at 16-36 weeks, and Australia recommending Tdap in the third trimester. In the United Kingdom, reduced diphtheriatetanus-pertussis-inactivated poliomyelitis vaccination is recommended during each pregnancy, ideally between 16 and 32 weeks [13].

Numerous authors have systematically assessed the safety profile, immunogenicity, and effectiveness of maternal immunization with Tdap and shown that it results in clinically and statistically significant reductions in mortality and morbidity of young children before they receive or complete their immunization schedules. One systematic review cited 90-93\% effectiveness against pertussis infection in children from birth to 59 days old [27]. Another study compared pertussis cases in young Argentinian infants whose mothers were immunized during pregnancy and who lived in states with high Tdap coverage-defined as $>50 \%$ versus those who lived in states with low maternal pertussis immunization coverage. There was a $51 \%$ relative reduction in the cohort whose mothers were immunized during pregnancy against pertussis [28]. In the United States, a network of managed care organizations examined the association of maternal pertussis vaccination with obstetric events and birth outcomes and found that of 123,000 singleton pregnancies occurring between 2010 and 2012, there were no adverse events or birth outcomes [29]. A recent study of 68,500 women in New Zealand did not find any association of vaccination in pregnancy with birth outcomes [30].

\section{Influenza}

Pregnant women and young children are more vulnerable to severe complications from influenza relative to the general population. Influenza is characterized by the sudden onset of constitutional and upper respiratory symptoms such as fever, myalgia, headache, malaise, non-productive cough, sore throat, and rhinitis. In young children, nausea, vomiting, and diarrhea may accompany influenza infection. Complications can include dehydration, pneumonia, sinusitis, otitis, encephalitis, or worsening of pre-existing medical issues [31]. Reports have documented an increase in influenza-related hospitalizations and deaths in pregnant women and their newborn infants during seasonal influenza outbreaks or pandemics [13, 32]. Fetuses are not exempt and are more likely to be stillborn, born prematurely, and/or have low birth weight if their mothers were infected with the influenza virus during pregnancy. The 1918 and 2009-2010 influenza A/H1N1 pandemics, which were associated with an increase in mortality and morbidity in these two groups, underscore these observations. A growing number of studies have examined the safety, immunogenicity, and effectiveness of pandemic influenza vaccines in pregnancy. One study from Norway reported that influenza diagnoses decreased by $70 \%$ when 117,000 pregnant women were given adjuvanted pandemic influenza vaccine [32]. In a Swiss cohort, maternal vaccination given at least 2 weeks before delivery during the 2010-2011 influenza season increased antibody titers in cord blood between 6- and 17-fold and provided seroprotection rates between 6- and 34-fold, depending on the strain and interval between vaccination and delivery [33]. In a matched case-control study in an urban hospital in the northeastern United States, influenza vaccine given to pregnant women was $91.5 \%$ effective in preventing hospitalizations (95\% confidence interval [CI]: 61.7-98.1, $P=$ 0.001 ) for infants aged $<6$ months [34]. Another study in three geographically diverse US counties reported the vaccine was $45 \%$ to $48 \%$ effective in preventing seasonal laboratory-confirmed influenza-related hospitalizations in infants aged $<6$ months between 2002 and 2009 (adjusted odds ratio $=0.52 ; 95 \%$ CI: $0.30-0.91$ ) [35]. Four randomized controlled trials, conducted in Mali, South Africa, Nepal, and Bangladesh, evaluated the efficacy of inactivated influenza vaccine administered during pregnancy [36-39]. Efficacy against laboratory-confirmed influenza in infants born to vaccinated mothers ranged from 30\% in Nepal to $63 \%$ in Bangladesh. Vaccine efficacy in mothers in Mali was 70.3\% (95\% CI: 42.2-85.8) and 50.4\% (95\% CI: 14.5-71.2) in non-HIV infected mothers in South Africa. Reductions in febrile respiratory illness were also reported in mothers in Bangladesh and Nepal (19\% [95\% CI: 1-34] and 36\% [95\% CI: 4-57], respectively).

Nevertheless, some authors are beginning to question the effects of maternal influenza vaccine on adverse birth outcomes [40]. For reasons that remain unclear, there is a welldocumented association between influenza infection and subsequent bacterial infections, especially pneumococcal infection and disease. For example, a US-based study conducted in a managed care organization reported higher efficacy of the pneumococcal conjugate vaccination against 
infant otitis media when mothers had received inactivated influenza vaccine [41].

Considering these data, WHO recommends that countries considering initiating or expanding seasonal influenza vaccination programs should identify pregnant women as the highest priority [42]. An increasing number of countries now recommend that all women who are pregnant or plan to get pregnant should receive seasonal inactivated influenza vaccine at any stage of pregnancy [43, 44]. And while use of live attenuated influenza vaccine for pregnant women is cautioned against, inadvertent administration does occur; one study examined a cohort of 834,999 pregnancies and identified 138 cases in which a woman had received a live attenuated influenza vaccine. There were no adverse fetal events and all other maternal outcomes occurred at similar rates to unvaccinated pregnant women [45].

Additional vaccines may be recommended for pregnant women in certain special situations (Table 1) [46-55].
Clinicians should be well versed in how to manage immunization appointments for their pregnant patients (Table 2) [56-58].

\section{New vaccines under development}

Many new vaccines are on the horizon and clinical trials are underway to assess their effectiveness in reducing and preventing maternal and newborn infections when administered to women prior to or during pregnancy. Some of these (e.g., vaccines to prevent Group B Streptococcus and respiratory syncytial virus) are intended primarily for administration to pregnant women. Others, including vaccines for hepatitis E, herpes simplex, Zika [59], and cytomegalovirus, would optimally be provided prior to pregnancy, given the associated morbidity and mortality in early pregnancy. There is also a growing need to include

Table 1 Vaccines for administration to pregnant women in special situations [46-55].

Vaccine Indication and recommendation

Pneumococcal vaccines

Yellow fever

Hepatitis A

Hepatitis B

Anthrax

Japanese encephalitis

Rabies

Polio

Cholera

Tick-borne encephalitis

Meningococcal conjugate (MenACWY and MenB recombinant)

Smallpox

Typhoid
The 23-valent pneumococcal polysaccharide vaccine is recommended for women with certain chronic health conditions. The 13-valent pneumococcal vaccine (PCV13) is recommended for women of immunocompromised status. PCV13 vaccine should only be provided to women when benefits outweigh risks.

Yellow fever vaccine is generally not recommended for pregnant women, but physicians should balance risks and benefits and provide the vaccine where travel, epidemics, or other exposure cause benefits to outweigh risks.

Recommended for women with increased risk of hepatitis A acquisition or complications, if not previously vaccinated.

Recommended for at-risk pregnant women based on behavioral or travel history or certain health conditions.

Recommended only where risk of exposure is high. At-risk pregnant women should receive anthrax vaccine adsorbed and 60 days of antimicrobial treatment.

Limited data on the safety, immunogenicity, and efficacy of the inactivated vaccine. The vaccine should be considered when outbreak, travel, or another exposure situation may pose a threat to the health of the mother and fetus and the potential benefit outweighs risk.

May be used where otherwise recommended. Given the risks associated with inadequate management, the vaccine is not contraindicated in pregnancy for post-exposure prophylaxis.

Inactivated poliovirus vaccine is indicated in outbreak situations, for travel to polio-endemic areas, or where exposure cannot be avoided, and when the benefits outweigh the risks. Oral poliovirus vaccine is contraindicated in pregnancy.

Targeted vaccination of high-risk groups in cholera outbreaks and endemic areas, including groups vulnerable to severe disease (such as pregnant women), where vaccination is not otherwise contraindicated.

Indicated for use in pregnant women where incidence of disease is high ( $>5$ cases/100,000 population per year). Risks and benefits should be weighed in areas where incidence is low. Indicated for travelers to endemic regions and in outbreak situations. The serogroup B vaccine should be deferred and provided to pregnant women only when the benefits outweigh the risks.

Small but serious potential risk to fetus associated with vaccination. The vaccine should not be provided to pregnant or periconceptual women except when they are at high risk of contracting the disease, given the severity of disease means that benefits outweigh risks.

Inactivated vaccine (Vi polysaccharide) recommended for pregnant women only when clearly indicated (outbreak or where risk of exposure is high). Live vaccines (Ty21a) are contraindicated in pregnancy. 
Table 2 For the clinician: immunizing pregnant women managing the antenatal care visit [56-58].

\begin{tabular}{|c|c|}
\hline Situation & Action \\
\hline Background & $\begin{array}{l}\text { - Vaccine coverage rates continue to be less than optimal for pregnant women. } \\
\text { - Provider recommendation is one of the strongest predictors of vaccine uptake in } \\
\text { pregnant women. }\end{array}$ \\
\hline Assessment & $\begin{array}{l}\text { - Evaluate the vaccination status of pregnant patients, including missing or } \\
\text { incomplete childhood vaccinations and other special conditions that may } \\
\text { warrant additional vaccinations. } \\
\text { - Only written records should be accepted as evidence of previous vaccination. }\end{array}$ \\
\hline $\begin{array}{l}\text { Counsel and } \\
\text { administer }\end{array}$ & $\begin{array}{l}\text { - Provide information on why the vaccine is needed, highlighting safety, efficacy, } \\
\text { and benefits to mom and infant. } \\
\text { - Acknowledge and address questions and concerns. } \\
\text { - Remind patient of the risks of nonvaccination. } \\
\text { - Make a strong recommendation for vaccination. } \\
\text { - Administer required vaccines. }\end{array}$ \\
\hline $\begin{array}{l}\text { Adverse event } \\
\text { reporting }\end{array}$ & $\begin{array}{l}\text { - Vaccine Adverse Event Reporting System and Vaccine Safety Datalink: for } \\
\text { broad populations. } \\
\text { - Vaccines and Medications in Pregnancy Surveillance System: for pregnant } \\
\text { populations. } \\
\text { - Vaccine-specific registries (e.g., for varicella, human papillomavirus, and herpes } \\
\text { zoster vaccines) focused on inadvertent immunization with live vaccines during } \\
\text { pregnancy. }\end{array}$ \\
\hline
\end{tabular}

pregnant women in the clinical development of epidemic vaccines; as such, WHO recently approved the inclusion of pregnant women in the deployment of an investigational Ebola vaccine [60].

\section{Respiratory syncytial virus vaccines}

Lower respiratory tract illness caused by respiratory syncytial virus (RSV) is the most common cause of serious and life-threatening pulmonary disease in infants, with the highest disease incidence within the first 3 months of life [61]. Protection of infants at risk of severe RSV disease has been shown through passive prophylaxis, including use of a monoclonal antibody, palivizumab (Synagis ${ }^{\circledR}$ ), but the high cost and need for multiple injections limits its use in low-income countries, where disease burden is greatest [62-66]. Infant vaccines against RSV have been in development for decades but have faced challenges, including the ability to elicit sufficient immunogenicity and safety concerns regarding an early whole virus vaccine candidate [67-70]. These concerns, along with the need to protect infants in early life and maternal immunization's track record of reducing influenza and pertussis in young infants, has prompted evaluation of maternal RSV vaccine candidates [48].

The most advanced vaccine candidate is a RSV prefusogenic F protein nanoparticle vaccine (NCT02624947) developed by Novavax, Inc. [71]. While the company announced in February 2019 that the candidate's phase 3 trial did not meet the primary objective of prevention of medically significant RSV lower respiratory tract illness, the vaccine was found safe in mothers and their infants through
180 days post-delivery [72]. Infants born to mothers vaccinated from 28 weeks to $<33$ weeks of pregnancy showed 53 percent vaccine efficacy rates against hospitalization with RSV lower respiratory tract infection (LRTI) and 70 percent against severe RSV hypoxemia through their first 90 days. The trial also demonstrated a $25 \%$ reduction in allcause LRTI hospitalizations and a 39\% reduction in allcause LRTI severe hypoxemia in infants observed through the first 180 days of life. A peer-reviewed manuscript is forthcoming. Although additional studies will be needed to meet regulatory and licensure requirements for this vaccine, these results begin to provide data to support proof of concept for maternal RSV vaccines. Three other early clinical-stage RSV F protein maternal vaccine candidates are currently in development, all of which are stabilized prefusion $\mathrm{F}$ protein vaccine candidates. Developers include Pfizer, New York, NY, USA (NCT03529773); GlaxoSmithKline, Brentford, UK (NCT02753413); and the US National Institute of Allergy and Infectious Diseases, Bethesda, MD, USA (NCT03049488) [73-75].

\section{Hepatitis E vaccines}

Hepatitis E virus (HEV) is the most common cause of acute viral hepatitis in adults in South Asia and Africa [76]. HEV occurrence during pregnancy, especially during the second and third trimesters, increases the risk of intrauterine fetal death, preterm delivery, and maternal death [77]. An Escherichia coli-expressed hepatitis E capsid protein vaccine adsorbed to aluminum salts $\left(\mathrm{Hecolin}^{\circledR}\right.$, Xiamen Innovax Biotech Co., Ltd., China) is approved for use in adults in China, but not yet approved elsewhere [78]. Vaccinating 
an at-risk pregnant woman against $\mathrm{HEV}$ could protect her and her unborn child. Furthermore, as anti-HEV IgG protects nonhuman primates from high-dose intravenous virus challenge [79], maternal immunization should transfer similarly protective maternal $\mathrm{IgG}$ to the fetus, potentially offering additional months of protection postpartum. In a large prospective cohort study of 2404 pregnant women in Nepal, where HEV is hyper-endemic, $>60 \%$ of subjects were susceptible, as they lacked detectable anti-HEV antibodies (Innis BL, unpublished data). A follow-up study is underway (NCT02759991) [80].

\section{Group B Streptococcus vaccines}

Group B Streptococcus (GBS) is a Gram-positive, opportunistic pathogen that colonizes the gastrointestinal and genitourinary tracts of up to $50 \%$ of healthy adults $[81,82]$. GBS exacts a significant mortality toll in neonates, young infants, and immunocompromised adults, and is a major cause of morbidity in pregnant women and the elderly [82]. Neonates are especially susceptible and develop septicemia, meningitis, and pneumonia [83].

Worldwide, vaginal colonization of GBS has been reported in between $12 \%$ and $27 \%$ of women [82]. During pregnancy, vaginal GBS colonization is believed to increase the incidence of premature delivery and perinatal transmission of the organism. GBS is also a leading cause of chorioamnionitis and is one of several bacteria thought to enhance the risk of preterm rupture of membranes $[84,85]$. Further, GBS is responsible for cases of endometriosis and urinary tract infections. It is now the most important cause of bacterial meningitis in infants under 3 months of age in countries reporting late-onset disease incidence [86, 87].

GBS infections in neonates are divided into early onset ( $<7$ days) and late onset disease. Maternal administration of intrapartum antibiotics prevents early-onset GBS disease but does not prevent late-onset disease [83]. Intrapartum antibiotic prophylaxis poses implementation challenges in lower-resourced settings and the potential impact of increased perinatal antibiotic use on neonatal gut microbiome as well as on antimicrobial resistance has raised concerns [88]. WHO has developed preferred product characteristics for GBS vaccines and called for the acceleration of vaccine development and licensure; [88, 89] phase 1 and 2 trials of GBS vaccine candidates intended for maternal administration are underway. One trivalent GBS vaccine candidate demonstrated acceptable safety and immunogenicity in nonpregnant and pregnant women [90]. Due to the large sample size required for phase 3 efficacy studies, efforts are underway to identify a serological correlate of protection as a basis for licensure [91, 92]. To date, no vaccine candidates have entered phase 3 trials.

\section{Cytomegalovirus, herpes simplex virus, Zika virus, and Ebola virus vaccines}

Cytomegalovirus (CMV) is a double-stranded herpes DNA virus. Congenital infection with $\mathrm{CMV}$ can be asymptomatic at birth in $85-90 \%$ of cases [93], although in $10-15 \%$ of neonates, infection is associated with microcephaly, periventricular calcifications, chorioretinitis, dermal hematopoiesis, thrombocytopenia, and progressive bilateral sensorineural hearing loss and impaired neurodevelopmental outcomes [94].

Several cytomegalovirus candidate vaccines are currently being evaluated in phase 1 and 2 clinical trials, however there are no phase 3 trials to date $[95,96]$.

Herpes simplex virus (HSV) is a double-stranded herpes DNA virus. The majority (95 percent) of neonatal infections result from virus presence in the vagina while $\sim 5 \%$ are transplacental. Transmission occasionally occurs via breast milk or contact with infected skin lesions. Primary maternal genital infection during pregnancy confers a 10-20 times higher risk compared with recurrent, secondary lesions because of higher viral replication, longer excretion rates from primary lesion and lack of maternal antibodies which can be passed to the infant. Three types of clinical presentations occur: in $20 \%$ of patients, a disseminated, systemic infection presents earliest (days 4-10 of life); in the most common type of perinatally acquired HSV, a skin, eye, and mucus membrane symptom complex predominate; and in up to 30 percent of cases, infection is localized to the central nervous system as encephalitis [93]. Prompt recognition, antiviral administration, and supportive treatment form the mainstay of therapeutic management [97]. Mortality is worst for disseminated disease, and long-term, neurodevelopmental morbidities worst with CNS disease. Herpes simplex candidate vaccines are being evaluated in clinical trials [98], however, conclusive protective benefit has not been established nor has licensure been granted [99].

Zika virus is a flavivirus transmitted by the Aedes aegypti mosquito. Increasing evidence suggests that in pregnant women, symptomatic, PCR-confirmed Zika infection results in neonates with microcephaly, neurological sequelae such as visual and hearing deficits, seizure activity, hypertonicity, spasticity, hyperreflexia, contractures, dysphagia, and feeding difficulties [100]. Zika infection in the first trimester results in worse sequelae than infections later in pregnancy [100]. Multiple Zika virus vaccine candidates are currently under investigation, including whole virus inactivated vaccines, nucleic acid vaccines, vectored vaccines, and protein-based and peptide-based candidates [101]. Some of these are currently in phase 1 and 2 trials [102]. An additional area of interest in Zika prophylaxis is the development of "therapeutic vaccines," which aim to prevent infection of the fetus in women infected with the Zika virus periconceptually or during pregnancy [103]. 
Table 3 Key considerations before introducing a new maternal vaccine $[112,113]$.

\begin{tabular}{ll}
\hline Issue & Key considerations \\
\hline Disease & - Public health and political priorities. \\
& - Alignment with global and regional recommendations. \\
& - Disease burden. \\
& - Status of other disease prevention and control measures. \\
- Eerformance and characteristics of available vaccines. & - Availability of vaccine supply. \\
Vaccine & Capability and capacity of immunization and maternal health programs, \\
& including infrastructure. \\
- Collaboration between immunization and maternal health programs. & - Continuous implementation of lessons learned. \\
& - Plans for introducing other new vaccines or maternal health services. \\
& - Opportunities for integration with current disease prevention or health \\
& initiatives. \\
\hline
\end{tabular}

Ebola virus are filoviridae that cause fever and nonspecific symptoms such as fatigue, dyspepsia and headache, which then progress to vomiting, diarrhea, bleeding, and abdominal pain. Due to the loss of gastrointestinal fluids and increased vascular permeability, patients may go on to develop shock, ultimately resulting in multiple organ failure and death. Ebola virus disease (EVD) is transmitted through contact with the bodily fluids (blood, urine, semen, saliva, sweat, and breast milk) of infected people or animals. Among pregnant women, case fatality rates in earlier outbreaks have ranged from 89 to $93 \%$ with universally $(100 \%)$ poor perinatal outcomes; the vast majority of pregnancies resulting in spontaneous abortion or stillbirth (78\%) and none of the live births $(22 \%)$ surviving beyond the third week of life [104]. Pregnant women despite having an enhanced risk of morbidity, mortality, and adverse birth outcomes associated with Ebola have been systematically excluded from Ebola vaccine trials and until recently were excluded from immunization, such as during the 2018 outbreak in the Kivu region of the Democratic Republic of the Congo (DRC), which deployed a replicating live virus vaccine, rVSV-ZEBOV-GP [105, 106]. In December 2018, the WHO Strategic Advisory Group of Experts (SAGE) on Immunization called for special consideration of pregnant and lactating women in EVD vaccine research. Three new non-replicating or replication deficient vaccines are currently in advanced stages of clinical evaluation or have been licensed [107]. SAGE provided updated interim recommendations in February 2019, announcing support for inclusion of pregnant women in vaccine trial protocols with the new vaccines $[105,106]$. As of October 2019, more than 840 pregnant women have received the vaccine with birth outcomes and safety data under consideration [108]. The rVSV-ZEBOV-GP vaccine was approved by the US Food and Drug Administration on 19 December 2019, with guidance that the "decision to vaccinate a woman who is pregnant should consider the woman's risk of exposure to
Zaire ebolavirus" [109, 110]. In February 2020 as part of "WHO Guidelines for the management of pregnant and breastfeeding women in the context of Ebola virus disease" a recommendation was made for these women to be offered vaccination with the prequalified rVSV-ZEBOV-GP vaccine "during an active Zaire EBOV outbreak in affected areas, in the context of rigorous research or in accordance with a compassionate use protocol" [111].

\section{Key considerations around maternal immunization introduction and use}

The WHO's general guidance to countries considering the introduction of new vaccines can be applied to maternal vaccines, with added health system strengthening and timing considerations (Table 3) [112, 113]. These considerations are especially important for maternal vaccines provided seasonally, such as influenza vaccines, and potentially future RSV vaccines, as they require a shortterm surge in the number of vaccines delivered and health system workload support.

The introduction and delivery of maternal vaccines often falls outside the reach of traditional immunization programs targeting young children and may require novel approaches to attain high coverage. Strategies for delivering maternal vaccines include routine delivery incorporated into existing services (antenatal, primary, and HIV care, and well and sick child visits), vaccination campaigns, and outreach [114]. Effective integration of maternal immunization into routine health care services, such as antenatal care, can provide an opportunity to strengthen and improve the maternal health platform through access to new resources; potentially increase uptake by improving the perception of the quality of care; and increase overall antenatal care attendance while also expanding vaccine delivery systems $[115,116]$. A coordinated, integrated delivery effort can 
ensure a "one-stop shop" where vaccines are available and offered to pregnant women where, when, and by the same provider they attend for pregnancy care. This approach will minimize missed opportunities for vaccination and provide continuity of care [117]. However, it necessitates close policy, fiscal, and programmatic coordination between EPI and maternal, newborn, and child health programs.

Low-resource settings that suffer disproportionate maternal and neonatal mortality, like sub-Saharan Africa and South Asia, may benefit the most from maternal immunization-but they may also face additional challenges due to inadequate infrastructure for safety monitoring [118, 119]. Strengthening the safety evidence base could address issues around risk perception and vaccine hesitancy and inform communication strategies. Reliable, robust tracking systems with the capacity to monitor implementation and outcomes will also provide information to assess vaccine effectiveness and delivery feasibility $[120,121]$.

\section{Available maternal immunization guidance}

Multiple guidance documents are available around development, decision-making, and introduction of maternal vaccines, with a focus on low-income settings [114, 122, 123]. WHO's vaccine research and development roadmaps for maternal vaccines against RSV and GBS outline priority activities for development, testing, licensure, and global availability of maternal RSV and GBS vaccines, respectively $[122,123]$. The Global Alliance to Prevent Prematurity and Stillbirth developed a set of references for maternal immunization safety monitoring in low- and middle-income countries and published a roadmap for improving reporting systems for adverse events following immunization, which evaluates the strengths and weaknesses of current systems and offers suggestions for addressing current gaps that include system strengthening [121]. The Advancing Maternal Immunization collaboration published a maternal immunization gap analysis and roadmap in 2018 to provide tools to help stakeholders navigate decision-making and successful introduction and uptake of maternal vaccines, with a focus on $\operatorname{RSV}$ [113, 124]; although those documents focus on a single vaccine, they offer a useful introduction framework for other maternal candidates currently in development.

\section{Noninfectious horizons for maternal immunization}

The effects of maternal immunization may go beyond infectious disease prevention. During pregnancy, maternal hypercholesterolemia is associated with markedly increased formation of fatty streaks in fetal arteries and accelerated development of atherosclerosis during normocholesterolemic childhood [125]. Oxidized low-density lipoproteins (OxLDL) accumulate in atherosclerotic lesions and are highly immunogenic. Immunizing rabbits and mice with various models of OxLDL is thought to induce antibodies that form complexes with circulating LDL. Immunization may also induce a switch from Th1 cells, which secrete proatherogenic interferon gamma, to Th2 cells that secrete antiatherogenic interleukins [126, 127]. Studies into whether immunizing rabbits and mice with OxLDL before pregnancy protected the fetus from atherogenic in-utero programming showed up to $56 \%$ reduced atherosclerosis in adult offspring. These studies also noted that maternal immunization with OxLDL caused a persistent change in specific postnatal B cell and antibody responses-in some cases, independent of transplacental passage of immunoglobulins. They concluded that maternal immunization with selected antigens may open a new preventive approach not solely for atherosclerosis, but for other immunemodulated diseases [128]. Similar conclusions can be made about the positive effects of maternal immunization on in-utero programming and subsequent reduction in offspring of insulin resistance, type 2 diabetes, and adult allergy-related responses [129, 130].

Another promising area is the use of maternal immunization to treat or prevent cancers. In a mouse model (BAL-neuT mice), mammary cancer progression in offspring prone to develop this cancer is inhibited when anti-neu DNA vaccination is given to mothers during pregnancy [131]. Childhood cancers, particularly neuroblastoma and lymphoma, may be most susceptible to maternal immunization [132, 133].

\section{Conclusion}

Mounting evidence suggests that maternal immunization is a safe and effective strategy to combat vaccine-preventable diseases. Numerous clinical trials are underway to investigate new maternal vaccine candidates. Successfully operationalizing a maternal immunization program will require integrated EPI and antenatal care systems to ensure standardized, efficient, and equitable operations and logistics, such that effective delivery occurs, pregnancy outcomes are improved, and many more lives are saved.

Acknowledgements We would like to thank Dr. Deborah Higgins for reading through different editions of this manuscript and making insightful edits. We also wish to acknowledge Katie Regan, Althea Burton, and Ruth Gebreselassie for their editorial assistance.

Funding Development of this publication was funded by the Bill \& Melinda Gates Foundation, Seattle, WA. The findings and conclusions 
contained within are those of the authors and do not necessarily reflect positions or policies of the Bill \& Melinda Gates Foundation, or of the World Health Organization.

Author contributions C.E., S.K., B.I., and J.A.F. conceived, designed, and wrote the work that led to this submission. A.S-t.M., J.M.S., and J.H. played an important role in interpreting the results and in providing additional writing support, research, and evidence. All authors reviewed and granted their final approval of this manuscript.

\section{Compliance with ethical standards}

Conflict of interest The authors declare that they have no conflict of interest.

Publisher's note Springer Nature remains neutral with regard to jurisdictional claims in published maps and institutional affiliations.

\section{References}

1. Andre FE, Booy R, Bock HL, Clemens J, Datta SK, John TJ, et al. Vaccination greatly reduces disease, disability, death and inequity worldwide. Bull World Health Organ. 2008;86:140-6.

2. Greenwood B. The contribution of vaccination to global health: past, present and future. Philos Trans R Soc Lond B Biol Sci. 2014;369:20130433.

3. Immunization Facts and Figures Nov 2015 Update. UNICEF, New York. Cited 18 Apr 2019. https://www.unicef.org/immuniza tion/files/Immunization_Facts_and_Figures_Nov_2015_update. pdf.

4. Levels \& Trends In Child Mortality: Report 2019 Estimates Developed by the UN Inter-agency Group for Child Mortality Estimation. UNICEF, New York. Cited 28 Oct 2019. https:// childmortality.org/wp-content/uploads/2019/10/UN-IGMEChild-Mortality-Report-2019.pdf.

5. Hedstrom A, Perez K, Umoren R, Batra M, Engmann C. Recent progress in global newborn health: thinking beyond acute to strategic care? J Perinatol. 2019;39:1031-41.

6. Marchant A, Sadarangani M, Garand M, Dauby N, Verhasselt V, Pereira L, et al. Maternal immunisation: collaborating with mother nature. Lancet Infect Dis. 2017;17:e197-208.

7. Omer SB. Maternal immunization. N Engl J Med. 2017;376: 1256-67.

8. Chu HY, Englund JA. Maternal immunization. Clin Infect Dis. 2014;59:560-8.

9. The Expanded Programme On Immunization: Benefits Of Immunization. World Health Organization, Geneva; 2013. Cited 30 Aug 2019. https://www.who.int/immunization/programmes_ systems/supply_chain/benefits_of_immunization/en/.

10. Bergin N, Murtagh J, Philip RK. Maternal vaccination as an essential component of life-course immunization and its contribution to preventive neonatology. Int $\mathrm{J}$ Environ Res Public Health. 2018;15:847.

11. Jamieson DJ, Honein MA, Rasmussen SA, Williams JL, Swerdlow DL, Biggerstaff MS, et al. H1N1 2009 influenza virus infection during pregnancy in the USA. Lancet. 2009;374:451-8.

12. Chaouat G, Petitbarat M, Dubanchet S, Rahmati M, Ledee N. Tolerance to the foetal allograft? Am J Reprod Immunol. 2010;63:624-36.

13. Vojtek I, Dieussaert I, Doherty TM, Franck V, Hanssens L, Miller J, et al. Maternal immunization: where are we now and how to move forward? Ann Med. 2018;50:193-208.
14. Mor G, Cardenas I. The immune system in pregnancy: a unique complexity. Am J Reprod Immunol. 2010;63:425-33.

15. Guttmacher AE, Maddox YT, Spong CY. The Human Placenta Project: placental structure, development, and function in real time. Placenta. 2014;35:303-4.

16. Palmeira P, Quinello C, Silveira-Lessa AL, Zago CA, CarneiroSampaio M. IgG placental transfer in healthy and pathological pregnancies. Clin Dev Immunol. 2012;2012:985646.

17. Calvert A, Jones CE. Placental transfer of antibody and its relationship to vaccination in pregnancy. Curr Opin Infect Dis. 2017;30:268-73.

18. Linder N, Ohel G. In utero vaccination. Clin Perinatol. 1994;21:663-74.

19. Engmann CM, Hodgson A, Aborigo R, Adongo PL, Moyer CA. Addressing the continuum of maternal and newborn care in Ghana: implications for policy and practice. Health Policy Plan. 2016;31:1355-63.

20. Roper MH, Vandelaer JH, Gasse FL. Maternal and neonatal tetanus. Lancet. 2007;370:1947-59.

21. Perez-Jacoiste Asin MA, Langbazounga M. Neonatal tetanus in an African newborn. Int J Infect Dis. 2018;67:1-2.

22. Maternal and Neonatal Tetanus Elimination (MNTE). World Health Organization, Geneva; 2019. Cited 30 Mar 2019. https:// www.who.int/immunization/diseases/MNTE_initiative/en/.

23. Thwaites CL, Beeching NJ, Newton CR. Maternal and neonatal tetanus. Lancet. 2015;385:362-70.

24. van der Maas NAT, Sanders EAM, Versteegh FGA, Baauw A, Westerhof A, de Melker HE. Pertussis hospitalizations among term and preterm infants: clinical course and vaccine effectiveness. BMC Infect Dis. 2019;19:919.

25. Yeung KHT, Duclos P, Nelson EAS, Hutubessy RCW. An update of the global burden of pertussis in children younger than 5 years: a modelling study. Lancet Infect Dis. 2017;17:974-80.

26. World Health Organization. Pertussis vaccines: WHO position paper, August 2015-Recommendations. Vaccine 2016;34: 1423-5.

27. Gkentzi D, Katsakiori P, Marangos M, Hsia Y, Amirthalingam G, Heath PT, et al. Maternal vaccination against pertussis: a systematic review of the recent literature. Arch Dis Child Fetal Neonatal Ed. 2017;102:F456-63.

28. Vizzotti C, Juarez MV, Bergel E, Romanin V, Califano G, Sagradini $S$, et al. Impact of a maternal immunization program against pertussis in a developing country. Vaccine. 2016;34: 6223-8.

29. Kharbanda EO, Vazquez-Benitez G, Lipkind HS, Klein NP, Cheetham TC, Naleway A, et al. Evaluation of the association of maternal pertussis vaccination with obstetric events and birth outcomes. JAMA. 2014;312:1897-904.

30. Griffin JB, Yu L, Watson D, Turner N, Walls T, Howe AS, et al. Pertussis immunisation in pregnancy safety (PIPS) study: a retrospective cohort study of safety outcomes in pregnant women vaccinated with Tdap vaccine. Vaccine. 2018;36:5173-9.

31. Clinical Signs \& Symptoms of Influenza. CDC, 2019. Cited 12 Feb 2020. https://www.cdc.gov/flu/professionals/acip/clinical.htm.

32. Haberg SE, Trogstad L, Gunnes N, Wilcox AJ, Gjessing HK, Samuelsen SO, et al. Risk of fetal death after pandemic influenza virus infection or vaccination. N Engl J Med. 2013;368:333-40.

33. Blanchard-Rohner G, Meier S, Bel M, Combescure C, OtheninGirard V, Swali RA, et al. Influenza vaccination given at least 2 weeks before delivery to pregnant women facilitates transmission of seroprotective influenza-specific antibodies to the newborn. Pediatr Infect Dis J. 2013;32:1374-80.

34. Benowitz I, Esposito DB, Gracey KD, Shapiro ED, Vazquez M. Influenza vaccine given to pregnant women reduces hospitalization due to influenza in their infants. Clin Infect Dis. 2010;51:1355-61. 
35. Poehling KA, Szilagyi PG, Staat MA, Snively BM, Payne DC, Bridges $\mathrm{CB}$, et al. Impact of maternal immunization on influenza hospitalizations in infants. Am J Obstet Gynecol. 2011;204: S141-8.

36. Tapia MD, Sow SO, Tamboura B, Teguete I, Pasetti MF, Kodio $\mathrm{M}$, et al. Maternal immunisation with trivalent inactivated influenza vaccine for prevention of influenza in infants in Mali: a prospective, active-controlled, observer-blind, randomised phase 4 trial. Lancet Infect Dis. 2016;16:1026-35.

37. Steinhoff MC, Katz J, Englund JA, Khatry SK, Shrestha L, Kuypers $\mathbf{J}$, et al. Year-round influenza immunisation during pregnancy in Nepal: a phase 4, randomised, placebo-controlled trial. Lancet Infect Dis. 2017;17:981-9.

38. Zaman K, Roy E, Arifeen SE, Rahman M, Raqib R, Wilson E, et al. Effectiveness of maternal influenza immunization in mothers and infants. N Engl J Med. 2008;359:1555-64.

39. Madhi SA, Cutland CL, Kuwanda L, Weinberg A, Hugo A, Jones $\mathrm{S}$, et al. Influenza vaccination of pregnant women and protection of their infants. N Engl J Med. 2014;371:918-31.

40. Jeong S, Jang EJ, Jo J, Jang S. Effects of maternal influenza vaccination on adverse birth outcomes: a systematic review and Bayesian meta-analysis. PLoS ONE. 2019;14:e0220910.

41. van Santen KL, Bednarczyk RA, Adjaye-Gbewonyo D, Orenstein WA, Davis R, Omer SB. Effectiveness of pneumococcal conjugate vaccine in infants by maternal influenza vaccination status. Pediatr Infect Dis J. 2013;32:1180-4.

42. Vaccines against influenza. WHO position paper November 2012. World Health Organization, Geneva; 2012. Cited 30 Mar 2019. https://www.who.int/immunization/position_papers/PP influenza_november2012_summary.pdf?ua $=1$.

43. Seasonal Influenza Vaccination in Europe - Overview of Vaccination Recommendations and Coverage Rates in the EU Member States for the 2012-13 Influenza Season. European Centre for Disease Prevention and Control, Stockholm. 2017. Cited 30 Mar 2019. https://ecdc.europa.eu/sites/portal/files/ media/en/publications/Publications/Seasonal-influenza-vaccina tion-Europe-2012-13.pdf.

44. Ortiz JR, Perut M, Dumolard L, Wijesinghe PR, Jorgensen P, Ropero AM, et al. A global review of national influenza immunization policies: Analysis of the 2014 WHO/UNICEF Joint Reporting Form on immunization. Vaccine. 2016;34:5400-5.

45. Toback SL, Beigi R, Tennis P, Sifakis F, Calingaert B, Ambrose CS. Maternal outcomes among pregnant women receiving live attenuated influenza vaccine. Influenza Other Respir Viruses. 2012;6:44-51.

46. Guidelines for Vaccinating Pregnant Women. CDC. 2016. Cited 30 Aug 2019. https://www.cdc.gov/vaccines/pregnancy/hcptoolkit/guidelines.html.

47. ACOG Committee Opinion. American College of Obstetricians and Gynecologists, Washington, DC. 2018. Cited 30 Aug 2019. https://www.acog.org/Clinical-Guidance-and-Publications/ Committee-Opinions/Immunization-Infectious-Disease-andPublic-Health-Preparedness-Expert-Work-Group/MaternalImmunization.

48. Munoz FM, Jamieson DJ. Maternal immunization. Obstet Gynecol. 2019;133:739-53.

49. Arunakumari PS, S K, Sahare A. Vaccination in pregnancy. Obstet Gynaecol. 2015;17:257-63.

50. World Health Organization. WHO position paper on hepatitis A vaccines - June 2012. Wkly Epidemiol Rec 2012;87: 261-76.

51. World Health Organization. Cholera vaccines: WHO position paper. Wkly Epidemiol Rec 2010;85:117-28.

52. World Health Organization. Japanese Encephalitis Vaccines: WHO position paper, February 2015-Recommendations. Vaccine 2016;34:302-3.
53. World Health Organization. Vaccines against tick-borne encephalitis: WHO position paper. Wkly Epidemiol Rec 2011;86:241-56.

54. World Health Organization. Vaccines and vaccination against yellow fever. WHO position paper - June 2013. Wkly Epidemiol Rec 2013;88:269-83.

55. World Health Organization. Global Advisory Committee on vaccine safety, 16-17 June 2010. Wkly Epidemiol Rec 2010;85: 285-92.

56. Lutz CS, Carr W, Cohn A, Rodriguez L. Understanding barriers and predictors of maternal immunization: Identifying gaps through an exploratory literature review. Vaccine. 2018;36:7445-55.

57. Ezeanolue E, Harriman K, Hunter P, Kroger A, Pellegrini C. General best practice guidelines for immunization. Best practices guidance of the Advisory Committee on Immunization Practices (ACIP) [Internet]. CDC. 2019. Cited 4 Sep 2019. https://www. cdc.gov/vaccines/hcp/acip-recs/general-recs/index.html.

58. Talking points for providers about immunization in pregnancy and postpartum. American College of Nurse-Midwives. 2014 Cited 4 Sep 2019. https://www.midwife.org/acnm/files/ccLibra ryFiles/Filename/000000004397/VaccinationTalkingPointsforProviders-091514.pdf.

59. Preferred product characteristics for a Zika vaccine for endemic use [Internet]. World Health Organization, Geneva; 2019. Cited 14 Oct 2019 14. https://www.who.int/immunization/research/ development/Preferred_Product_Characteristics_endemc_use_a fter_public_consultation_21August.pdf?ua $=1$.

60. Krubiner CB, Faden RR, Karron RA, Little MO, Lyerly AD, Abramson JS, et al. Pregnant women \& vaccines against emerging epidemic threats: ethics guidance for preparedness, research, and response. Vaccine 2019;S0264-410X:30045-3.

61. Nair H, Simoes EA, Rudan I, Gessner BD, Azziz-Baumgartner E, Zhang JSF, et al. Global and regional burden of hospital admissions for severe acute lower respiratory infections in young children in 2010: a systematic analysis. Lancet. 2013;381:1380-90.

62. The PREVENT Study Group. Reduction of respiratory syncytial virus hospitalization among premature infants and infants with bronchopulmonary dysplasia using respiratory syncytial virus immune globulin prophylaxis. Pediatrics. 1997;99:93-9.

63. The IMpact-RSV Study Group. Palivizumab, a humanized respiratory syncytial virus monoclonal antibody, reduces hospitalization from respiratory syncytial virus infection in high-risk infants. Pediatrics. 1998;102:531-7.

64. Feltes TF, Cabalka AK, Meissner HC, Piazza FM, Carlin DA, Top FH Jr., et al. Palivizumab prophylaxis reduces hospitalization due to respiratory syncytial virus in young children with hemodynamically significant congenital heart disease. J Pediatr. 2003;143:532-40.

65. Andabaka T, Nickerson JW, Rojas-Reyes MX, Rueda JD, Bacic Vrca V, Barsic B. Monoclonal antibody for reducing the risk of respiratory syncytial virus infection in children. Cochrane Database Syst Rev 2013:Cd006602.

66. Shi T, McAllister DA, O’Brien KL, Simoes EAF, Madhi SA, Gessner BD, et al. Global, regional, and national disease burden estimates of acute lower respiratory infections due to respiratory syncytial virus in young children in 2015: a systematic review and modelling study. Lancet. 2017;390:946-58.

67. Kim HW, Canchola JG, Brandt CD, Pyles G, Chanock RM, Jensen $\mathrm{K}$, et al. Respiratory syncytial virus disease in infants despite prior administration of antigenic inactivated vaccine. Am J Epidemiol. 1969;89:422-34.

68. Kapikian AZ, Mitchell RH, Chanock RM, Shvedoff RA, Stewart CE. An epidemiologic study of altered clinical reactivity to respiratory syncytial (RS) virus infection in children previously vaccinated with an inactivated RS virus vaccine. Am J Epidemiol. 1969;89:405-21. 
69. Fulginiti VA, Eller JJ, Sieber OF, Joyner JW, Minamitani M, Meiklejohn G. Respiratory virus immunization. I. A field trial of two inactivated respiratory virus vaccines; an aqueous trivalent parainfluenza virus vaccine and an alum-precipitated respiratory syncytial virus vaccine. Am J Epidemiol. 1969;89:435-48.

70. Chin J, Magoffin RL, Shearer LA, Schieble JH, Lennette EH. Field evaluation of a respiratory syncytial virus vaccine and a trivalent parainfluenza virus vaccine in a pediatric population. Am J Epidemiol. 1969;89:449-63.

71. Swamy GK, Munoz FM, Polack SA, Madhi SA, Trenholme AA, Simoes EAF, et al. Safety of Third Trimester Immunization with a Respiratory Syncytial Virus (RSV) F Protein Vaccine and Protection of Infants Over The First 180 days of Life Against All-cause Lower Respiratory Tract Infection. Novavax.com. 2019. Cited 4 Sept 2019. https://www.novavax.com/download/ files/20190808-IDSOG-Presentation.pdf.

72. Novavax Announces Topline Results from Phase 3 PrepareTM Trial of ResVaxTM for Prevention of RSV Disease in Infants via Maternal Immunization. Gaithersburg, Novavax. 2019. Cited 31 Jan 2020. http://ir.novavax.com/news-releases/news-release-deta ils/novavax-announces-topline-results-phase-3-preparetm-trial

73. ClinicalTrials.gov. Bethesda (MD): National Library of Medicine (US). Identifier NCT03529773, A Study to Describe The Safety And Immunogenicity OF A RSV Vaccine In Healthy Adults. 2019. Cited 4 Sep 2019. https://clinicaltrials.gov/ct2/ show/NCT03529773.

74. ClinicalTrials.gov. Bethesda (MD): National Library of Medicine (US). Identifier NCT02753413, Safety and reactogenicity study of GlaxoSmithKline (GSK) Biologicals' Investigational Respiratory Syncytial Virus (RSV) vaccine (GSK3003891A) in healthy women. 26 Jun 2018. Cited 4 Sep 2019. https://clinica 1trials.gov/ct2/show/NCT02753413.

75. ClinicalTrials.gov. Bethesda (MD): National Library of Medicine (US). Identifier NCT03049488, Dose, Safety, Tolerability And Immunogenicity Of A Stabilized Prefusion RSV F Subunit Protein Vaccine, VRC-RSVRGP084-00-VP (DS-Cav1), Alone Or With Alum Adjuvant, In Healthy Adults. 6 Sep 2019. Cited 13 Sept 2019. https://clinicaltrials.gov/ct2/show/NCT03049488.

76. Teshale EH, Hu DJ. Hepatitis E: epidemiology and prevention. World J Hepatol. 2011;3:285-91.

77. Jin H, Zhao Y, Zhang X, Wang B, Liu P. Case-fatality risk of pregnant women with acute viral hepatitis type E: a systematic review and meta-analysis. Epidemiol Infect. 2016;144:2098-106.

78. Innis BL. Lynch JA. Immunization against hepatitis E. Cold Spring Harb Perspect Med 2018;8:a032573.

79. Tsarev SA, Tsareva TS, Emerson SU, Govindarajan S, Shapiro M, Gerin JL, et al. Successful passive and active immunization of cynomolgus monkeys against hepatitis E. Proc Natl Acad Sci USA. 1994;91:10198-202.

80. ClinicalTrials.gov [Internet]. Bethesda (MD): National Library of Medicine (US). Identifier NCT02759991, Effectiveness Trial To Evaluate Protection Of Pregnant Women By Hepatitis E Vaccine In Bangladesh. 2019. Cited 4 Sep 2019. https://clinica ltrials.gov/ct2/show/NCT02759991.

81. Lawn JE, Bianchi-Jassir F, Russell NJ, Kohli-Lynch M, Tann CJ, Hall J, et al. Group B streptococcal disease worldwide for pregnant women, stillbirths, and children: why, what, and how to undertake estimates? Clin Infect Dis. 2017;65:S89-99.

82. Johri AK, Paoletti LC, Glaser P, Dua M, Sharma PK, Grandi G, et al. Group B Streptococcus: global incidence and vaccine development. Nat Rev Microbiol. 2006;4:932-42.

83. Bauserman MS, Laughon MM, Hornik CP, Smith PB, Benjamin DK Jr., Clark RH, et al. Group B Streptococcus and Escherichia coli infections in the intensive care nursery in the era of intrapartum antibiotic prophylaxis. Pediatr Infect Dis J. 2013;32:208-12.
84. Ferrieri P, Cleary PP, Seeds AE. Epidemiology of group-B streptococcal carriage in pregnant women and newborn infants. $J$ Med Microbiol. 1977;10:103-14.

85. Galask RP, Varner MW, Petzold CR, Wilbur SL. Bacterial attachment to the chorioamniotic membranes. Am J Obstet Gynecol. 1984;148:915-28.

86. Thigpen MC, Whitney CG, Messonnier NE, Zell ER, Lynfield R, Hadler JL, et al. Bacterial meningitis in the United States, 19982007. N. Engl J Med. 2011;364:2016-25.

87. Sadarangani M, Willis L, Kadambari S, Gormley S, Young Z, Beckley R, et al. Childhood meningitis in the conjugate vaccine era: a prospective cohort study. Arch Dis Child. 2015;100: 292-4.

88. Vekemans J, Moorthy V, Friede M, Alderson MR, Sobanjo-Ter Meulen A, Baker CJ, et al. Maternal immunization against Group B streptococcus: World Health Organization research and development technological roadmap and preferred product characteristics. Vaccine. 2019;37:7391-3.

89. WHO preferred product characteristics for Group B Streptococcus vaccines. World Health Organization, Geneva; 2017. Cited 31 Jan 2020. https://apps.who.int/iris/bitstream/handle/ 10665/258703/WHO-IVB-17.09-eng.pdf;jsessionid= 36A8939A60BA1AF3882CA64CE699E75A? sequence $=1$.

90. Madhi SA, Cutland CL, Jose L, Koen A, Govender N, Wittke F, et al. Safety and immunogenicity of an investigational maternal trivalent group B streptococcus vaccine in healthy women and their infants: a randomised phase $1 \mathrm{~b} / 2$ trial. Lancet Infect Dis. 2016;16:923-34.

91. Le Doare K, Kampmann B, Vekemans J, Heath PT, Goldblatt D, $\mathrm{Nahm} \mathrm{MH}$, et al. Serocorrelates of protection against infant group B streptococcus disease. Lancet Infect Dis. 2019;19: e162-71.

92. Vekemans J, Crofts J, Baker CJ, Goldblatt D, Heath PT, Madhi $\mathrm{SA}$, et al. The role of immune correlates of protection on the pathway to licensure, policy decision and use of group B Streptococcus vaccines for maternal immunization: considerations from World Health Organization consultations. Vaccine. 2019;37:3190-8.

93. Brodsky D, Martin C Neonatology Review. Hanley \& Belfus Inc., Philadelphia PA, United States, 2010.

94. Giannattasio A, Di Costanzo P, De Matteis A, Milite P, De Martino D, Bucci L, et al. Outcomes of congenital cytomegalovirus disease following maternal primary and non-primary infection. J Clin Virol. 2017;96:32-6.

95. ClinicalTrials.gov. Bethesda (MD): National Library of Medicine (US). Identifier NCT01376778, A Randomized Trial To Prevent Congenital Cytomegalovirus (CMV) (CMV). 2011. Cited 12 Feb 2020. https://clinicaltrials.gov/ct2/show/ NCT01376778.

96. CMV Vaccines And Clinical Trials. National CMV Foundation. Cited 12 Feb 2020. https://www.nationalcmv.org/overview/va ccine-development.

97. Shah SS, Aronson PL, Mohamad Z, Lorch SA. Delayed acyclovir therapy and death among neonates with herpes simplex virus infection. Pediatrics. 2011;128:1153-60.

98. Mahant S, Hall M, Schondelmeyer AC, Berry JG, Kimberlin DW, Shah SS. Neonatal Herpes Simplex Virus infection among medicaid-enrolled children: 2009-15. Pediatrics 2019;143: e20183233.

99. Schiffer JT, Gottlieb SL. Biologic interactions between HSV-2 and HIV-1 and possible implications for HSV vaccine development. Vaccine. 2019;37:7363-71.

100. Hoen B, Schaub B, Funk AL, Ardillon V, Boullard M, Cabie A, et al. Pregnancy outcomes after ZIKV infection in French Territories in the Americas. N Engl J Med. 2018;378:985-94. 
101. Poland GA, Kennedy RB, Ovsyannikova IG, Palacios R, Ho PL, Kalil J. Development of vaccines against Zika virus. Lancet Infect Dis. 2018;18:e211-9.

102. Barrett ADT. Current status of Zika vaccine development: Zika vaccines advance into clinical evaluation. NPJ Vaccines. 2018;3:24.

103. Schwartz DA. Clinical trials and administration of Zika virus vaccine in pregnant women: lessons (that should have been) learned from excluding immunization with the Ebola Vaccine during pregnancy and lactation. Vaccines. 2018;6:E81.

104. Bebell LM, Oduyebo T, Riley LE. Ebola virus disease and pregnancy: a review of the current knowledge of Ebola virus pathogenesis, maternal, and neonatal outcomes. Birth Defects Res. 2017;109:353-62.

105. Preliminary Results On The Efficacy Of rVSV-ZEBOV-GP Ebola Vaccine Using The Ring Vaccination Strategy In The Control Of An Ebola Outbreak In The Democratic Republic Of The Congo: An Example Of Integration Of Research Into Epidemic Responses. World Health Organization, Geneva; 2019. Cited 31 Jan 2020. https://www.who.int/csr/resources/publica tions/ebola/ebola-ring-vaccination-results-12-april-2019.pdf.

106. SAGE Interim Recommendations On Vaccination Against Ebola Virus Disease (EVD). World Health Organization, Geneva; 2019. Cited 31 Jan 2020. https://www.who.int/immunization/ interim_ebola_recommendations_feb_2019.pdf.

107. Meeting of the strategic advisory group of experts on immunization, October 2018 - conclusions and recommendations. Weekly Epidemiological Record 2018;93:661-80. World Health Organization, Geneva. Cited 31 Jan 2020. https://www.who. int/wer/2018/wer9349/en/.

108. Schwartz DA. Being pregnant during the Kivu Ebola virus outbreak in DR Congo: The rVSV-ZEBOV vaccine and its accessibility by mothers and infants during humanitarian crises and in conflict areas. Vaccines. 2020;8:E38.

109. Ebola (Ebola virus disease). CDC. 2019. Cited 31 Jan 2020. https://www.cdc.gov/vhf/ebola/prevention/index.html.

110. ERVEBO package insert. Merck \& Co, Inc, 2019. Cited 31 Jan 2020. https://www.fda.gov/media/133748/download.

111. Guidelines For The Management Of Pregnant And Breastfeeding Women In The Context Of Ebola Virus Disease. World Health Organization, Geneva; 2020. Cited 20 Feb 2020. https://www. who.int/reproductivehealth/publications/ebola-pregnant-and-brea stfeeding-women/en/.

112. Principles And Considerations For Adding A Vaccine To A National Immunization Programme. World Health Organization, Geneva; 2014. Cited 4 Sep 2019. https://apps.who.int/iris/bitstrea $\mathrm{m} /$ handle/10665/111548/9789241506892_eng.pdf;jsessionid $=$ 4350DF935454AC1BFCC4A94595BAEA8B? sequence $=1$.

113. PATH. Advancing RSV maternal immunization: a gap analysis report. PATH, Seattle. 2018. Cited 4 Sep 2019. https://path. azureedge.net/media/documents/Advancing_RSV_Maternal_ Immunization_A_Gap_Analysis_Report.pdf

114. How To Implement Influenza Vaccination Of Pregnant Women: An Introduction Manual For National Immunization Programme Managers And Policy Makers (WHO/IVB/16.06). World Health Organization, Geneva; 2017. Cited 4 Sep 2019. https://apps.who. int/iris/bitstream/handle/10665/250084/WHO-IVB-16.06-eng. pdf? sequence $=1$.

115. Bardaji A, MacDonald NE, Omer SB, Aguado T. Maternal immunization: a call to accelerate progress. Vaccine. 2019;37: 2882-3.

116. de Jongh TE, Gurol-Urganci I, Allen E, Zhu NJ, Atun R. Integration of antenatal care services with health programmes in lowand middle-income countries: systematic review. J Glob Health. 2016;6:010403.
117. Olorunsaiye CZ, Langhamer MS, Wallace AS, Watkins ML. Missed opportunities and barriers for vaccination: a descriptive analysis of private and public health facilities in four African countries. Pan Afr Med J. 2017;27:6.

118. Hug L, Alexander M, You D, Alkema L. National, regional, and global levels and trends in neonatal mortality between 1990 and 2017, with scenario-based projections to 2030: a systematic analysis. Lancet Glob Health. 2019;7:e710-20.

119. Trends In Maternal Mortality: 1990-2015: Estimates From WHO, UNICEF, UNFPA, World Bank Group and the United Nations Population Division. World Health Organization, Geneva; 2015. Cited 4 Sep 2019. https://apps.who.int/iris/bitstream/ handle/10665/194254/9789241565141_eng.pdf?sequence= $1 \&$ isAllowed $=\mathrm{y}$.

120. Sobanjo-Ter Meulen A, Munoz FM, Kaslow DC, Klugman KP, Omer SB, Vora P, et al. Maternal interventions vigilance harmonization in low- and middle-income countries: stakeholder meeting report; Amsterdam, May 1-2, 2018. Vaccine. 2019;37:2643-50.

121. GAPPS. Maternal Immunization Safety Monitoring In Low- And Middle-income Countries: A Roadmap For Program Development. Global Alliance to Prevent Prematurity and Stillbirth, Seattle, WA. 2017. Cited 4 Sep 2019. https://www.gapps.org/ PDF/MaternalImmunizationSafetyMonitoringInLMICs.pdf.

122. RSV Vaccine Research And Development Technology Roadmap: Priority Activities For Development, Testing, Licensure And Global Use Of Rsv Vaccines, With A Specific Focus On The Medical Need For Young Children In Low- And Middleincome Countries. World Health Organization, Geneva; 2017. Cited 4 Sep 2019. http://www.who.int/iris/handle/10665/258706.

123. Group B Streptococcus Vaccine Development Technology ROADMAP Priority Activities For Development, Testing, Licensure And Global Availability Of Group B Streptococcus Vaccines. World Health Organization, Geneva; 2017. Cited 4 Sept 2019. https://apps.who.int/iris/bitstream/handle/10665/ 258704/WHO-IVB-17.10-eng.pdf.

124. PATH. A roadmap for advancing RSV maternal immunization. PATH, Seattle. 2018. Cited 4 Sep 2019. https://path.azureedge. net/media/documents/PATH-AMI_RSV_MI_Roadmap_ FINAL_103118.pdf.

125. Napoli C, D’Armiento FP, Mancini FP, Postiglione A, Witztum JL, Palumbo G, et al. Fatty streak formation occurs in human fetal aortas and is greatly enhanced by maternal hypercholesterolemia. Intimal accumulation of low density lipoprotein and its oxidation precede monocyte recruitment into early atherosclerotic lesions. J Clin Invest. 1997;100:2680-90.

126. Napoli C, Glass CK, Witztum JL, Deutsch R, D’Armiento FP, Palinski W. Influence of maternal hypercholesterolaemia during pregnancy on progression of early atherosclerotic lesions in childhood: fate of early lesions in children (FELIC) study. Lancet. 1999;354:1234-41.

127. Napoli C, Witztum JL, Calara F, de Nigris F, Palinski W. Maternal hypercholesterolemia enhances atherogenesis in normocholesterolemic rabbits, which is inhibited by antioxidant or lipid-lowering intervention during pregnancy: an experimental model of atherogenic mechanisms in human fetuses. Circ Res. 2000;87:946-52.

128. Yamashita T, Freigang S, Eberle C, Pattison J, Gupta S, Napoli $\mathrm{C}$, et al. Maternal immunization programs postnatal immune responses and reduces atherosclerosis in offspring. Circ Res. 2006;99:e51-64.

129. Eberle C, Merki E, Yamashita T, Johnson S, Armando AM, Quehenberger O, et al. Maternal immunization affects in utero programming of insulin resistance and type 2 diabetes. PLoS ONE. 2012;7:e45361. 
130. Melkild I, Groeng EC, Leikvold RB, Granum B, Lovik M. Maternal allergen immunization during pregnancy in a mouse model reduces adult allergy-related antibody responses in the offspring. Clin Exp Allergy. 2002;32:1370-6.

131. Barutello G, Curcio C, Spadaro M, Arigoni M, Trovato R, Bolli E, et al. Antitumor immunization of mothers delays tumor development in cancer-prone offspring. Oncoimmunology. 2015;4: e1005500.
132. Chiarle R, Martinengo C, Mastini C, Ambrogio C, D'Escamard $\mathrm{V}$, Forni $\mathrm{G}$, et al. The anaplastic lymphoma kinase is an effective oncoantigen for lymphoma vaccination. Nat Med. 2008;14: 676-80.

133. Riccardo F, Real A, Voena C, Chiarle R, Cavallo F, Barutello G. Maternal immunization: new perspectives on its application against non-infectious related diseases in newborns. Vaccines. 2017;5:20. 